\title{
The influence of different level of opponents on internal responses and external loads during small-sided games in soccer
}

\author{
Karel Hůlka*, Radim Weisser, Jan Bělka, and Pavel Háp \\ Faculty of Physical Culture, Palacký University Olomouc, Olomouc, Czech Republic
}

Copyright: (C) 2015 K. Hůlka et al. This is an open access article licensed under the Creative Commons Attribution License (http://creativecommons.org/licenses/by/4.0/).

\begin{abstract}
Background: Small-sided games belong to specific training where exercise intensity can be manipulated mainly by modifying external factors. To ensure suitable usage of small-sided games in practice, we have to know the variables, which could influence internal responses and external loads. Objective: The purpose of this work is to determine the influence of opponents of different levels on internal response and external load during a 4-a-side soccer game. Methods: Twenty physical education and soccer coaching students (age $22.53 \pm 1.02$ years; body mass index $20.83 \pm 2.13 \mathrm{~kg} \cdot \mathrm{m}^{-2}$; peak heart rate $195.26 \pm 6.05$ beats $\cdot \mathrm{min}^{-1}$ ) participated in the study. Heart rate, distance covered, global rate of perceived exertion, and technical demands (passes, shots, steals, turnovers) were monitored. The participants were divided into two higher level teams and two lower level teams according to experts' perfomance ranking. Results: The results showed significantly lower average heart rate achieved by higher level teams in the 4-a-side game against lower level opponents compared to against higher level teams. Then lower level teams reached significantly higher average heart rate in the 4-a-side game against higher level teams than in mutual lower level team 4-a-side game. We found out significantly higher distance covered by lower level teams in 4-a-side game against higher level teams than in lower level teams mutual 4-a-side game. Conclusions: The results of this study demonstrated that the performance level of opponents influence internal and external load of the players. The higher level of opponents increases the work load of lower level teams.
\end{abstract}

Keywords: heart rate, specificity, tactical metabolic training, distance covered

\section{Introduction}

Match analyses of player's match performance (Alexandre et al., 2012) showed that soccer is sport of acyclic nature and intensity (Mallo \& Navarro, 2007), it is classified as a high intensity intermittent sport (Bangsbo, Mohr, \& Krustrup, 2006; McMillan, Helgerud, Macdonald, \& Hoff, 2005). Distances covered at the top level are $10-12 \mathrm{~km}$ for the field players, average work intensity moves around anaerobic threshold (Stolen, Chamari, Castagna, \& Wisloff, 2005), and the players perform 1000-1400 short activities such as acceleration, changes of direction with changes of activity patterns (Sjokvist et al., 2011). Mean heart rate moves from 160 to 170 beats per minute during a soccer game (Mohr, Krustrup, \& Bangsbo, 2005). Because of the game duration, soccer

\footnotetext{
* Address for correspondence: Karel Hůlka, Department of Sport, Faculty of Physical Culture, Palacký University Olomouc, třída Míru 117, 77111 Olomouc, Czech Republic. E-mail: karel.hulka@upol.cz
}

is mainly dependent upon aerobic metabolism (Stolen et al., 2005) that is why specific aerobic conditioning is needed (Stone \& Kilding, 2009).

Success in soccer is dependent on multitude factors (Little \& Williams, 2006) such as physiological, technical, and tactical skills (Hoff, Wisloff, Engen, Kemi, \& Helgerud, 2002). Small-sided games (SSGs) became popular method of developing soccer specific aerobic fitness (Impellizzeri et al., 2006). SSGs are modern means of specific training where exercise intensity can be manipulated mainly by modifying external factors (Hill-Haas, Dawson, Impellizzeri, \& Coutts, 2011). Little and Williams (2006), and Reilly (2005) indicated that high specificity of loading, decision making under pressure of opponents, and keeping players motivated were the most important advantages of using smallsided games in soccer training. Thus, researchers have examined variables that may affect the intensity of SSGs such as dimensions of the pitch (Casamichana \& Castellano, 2010), number of players (Aslan, 2013; Castellano, Casamichana, \& Dellal, 2013), rule modifications 
(Mallo \& Navarro, 2007), continuous and intermittent modality (Impellizzeri et al., 2006), goalkeepers' participation (da Silva et al., 2011; Hill-Haas, Coutts, Rowsell, $\&$ Dawson, 2008), and coach encouragement (Rampinini et al., 2007).

Koklu, Ersoz, Alemdaroglu, Asc, and Ozkan (2012) showed that method of team formation could influence the exercise intensity and in their work they compared work intensity of players in teams formatted by different methods based on level of technical, tactical, or physical performance. Dellal, Hill-Haas, Lago-Penas, and Chamari (2011) found differences between the work intensity of amateur and professional players in smallsided games but only in their mutual game. In this study we want to support these research gaps and determine the influence of different level of opponents to internal response and external load during 4-a-side soccer games.

\section{Methods}

\section{Participants}

Twenty physical education and soccer coaching students of Palacký University Olomouc, Czech Republic participated in the study. All students were active players in the fourth and fifth Czech division. The participants were divided (for description of division see Procedures section) into higher level performance group (age $22.37 \pm 1.23$ years; body massindex $20.25 \pm 1.26 \mathrm{~kg} \cdot \mathrm{m}^{-2}$; peak heart rate $196.60 \pm 4.99$ beats $\cdot \mathrm{min}^{-1}$ ) and lower level performance group (age 22.70 \pm 0.67 years; body mass index $21.30 \pm 1.55 \mathrm{~kg} \cdot \mathrm{m}^{-2}$; peak heart rate $194.31 \pm 4.08$ beats $\left.\cdot \mathrm{min}^{-1}\right)$. The group of students was deliberately chosen to highlight the performance differences between higher and lower level teams. All procedures were conducted after the competitive part of the season (June and July 2014). Participation was voluntary and players could withdraw from the study at any time. The aims and objectives of the present study have been clarified to all participants and all of them gave a voluntary written informed consent.

\section{Procedures}

The peak heart rate $\left(\mathrm{HR}_{\text {peak }}\right)$ values were measured by means of the Yo-Yo intermittent level recovery test (Bangsbo, Iaia, \& Krustrup, 2008) and were established for each player individually (Krustrup et al., 2006). The lower level group covered the $1285.46 \pm 485.88 \mathrm{~m}$ and higher level teams $1318.17 \pm 418.87 \mathrm{~m}$. All the players were familiar with this test because they had performed it as a regular part of a conditioning test before and during the season. Heart rate measures were performed using the TEAM Polar ${ }^{2}$ Pro system (Polar Electro, Kempele, Finland).
During the first measured practice the participants were evaluated by three experts during a 4-a-side game based on their participation in the team performance and a ranking was made. The participants were divided into two higher level teams (HLT; ten best players) and two lower level teams (LLT) according to the ranking. Each team consisted of five players. Subsequently the tournament was created and during the following three weeks every team played one 4-a-side game per week. Each team played three 4-a-side games.

The videos of the 4-a-side games were recorded with two Canon HF10 video cameras (each with a resolution of $1280 \times 720$ pixels). Each camera was used to record a separate half of the court. One camera was placed perpendicular to the side line $(620 \mathrm{~cm}$ above the surface, $840 \mathrm{~cm}$ from the side line) in the middle of the first recorded half of the court. The second camera was placed in an analogous manner to record the second half of the court. To obtain distance covered (an indicator of external load) the video records of small-sided games were analysed by a standardised procedure using a software package Video Manual Motion Tracker 1.0 (Hulka, Cuberek, \& Svoboda, 2014). Recorded 4-a-side games were observed by one expert to determine the technical scores for each team performed during each 4-a-side game. Technical demands were divided into five categories (passes, pass accuracy, shots on goal, steals, and turnovers).

The heart rate was monitored during all measurements by TEAM Polar ${ }^{2}$ Pro system (Polar Electro, Kempele, Finland) and the results were expressed by a percentage of $\mathrm{HR}_{\text {peak }}$ of each participant. Global rate of perceived exertion was recorded just after the 4-a-side games using the Borg scale (RPE, category rate scale 1-10) to evaluate the subjective psycho-physiological strain of the players (Castagna, Impellizzeri, Chaouachi, Ben Abdelkrim, \& Manzi, 2011). The participants were instructed and familiarized with the scale at the end of the two sessions before starting the measurement sessions.

\section{4-a-side soccer game (4v4SSG)}

The observed participants used blue T-shirts with large orange numbers (corresponding with official soccer rules) to permit clear identification. The 4-a-side soccer games were played on the $40 \times 20 \mathrm{~m}\left(100 \mathrm{~m}^{2}\right.$ per player $)$ court with small handball goals $(3 \times 2 \mathrm{~m})$ in the sports hall with wooden floor. The $4 \mathrm{v} 4 \mathrm{SSG}$ were played $4 \mathrm{v} 4$ players with goalkeepers. One $4 \mathrm{v} 4 \mathrm{SSG}$ consisted of two four minutes periods with three minutes of recovery. During the research one mutual game of HLTs, one mutual game of LLTs and two games of HLTs against LLTs were played. 


\section{Statistical analyses}

Software SPSS (Version 17; SPSS, Chicago, IL, USA) was used to process the data. Descriptive statistics mean and standard deviation (s) were used to describe participant's performance during the SSGs. The average heart rate values measured during the SSGs were compared. To compare gained data a one-way ANOVA and Bonferroni post-hoc test were used. ANOVA preconditions were checked by the Lilliefors test of normality and Leven test of homogeneity. The results were completed by effect size calculation:

$\omega^{2}=[F \cdot(k-1)]-k+1 /[F \cdot(k-1)]+n-k+1$,

where $F$ is ANOVA value, $k$ is number of groups, and $n$ is a sample size. The statistical significances of all parts of the analysis were determined at $\alpha<.05$.

\section{Results}

The average heart rate of higher level teams in the 4v4SSG against lower level teams (LLTs) was
$149.88 \pm 10.82$ beats $\cdot \min ^{-1}\left(77.92 \pm 4.05 \%\right.$ of $\left.\mathrm{HR}_{\text {peak }}\right)$ and $\quad 161.73 \pm 7.05$ beats $\cdot \mathrm{min}^{-1} \quad(84.86 \pm 2.05 \%$ of $\mathrm{HR}_{\text {peak }}$ ) against higher level teams (HLTs). The average heart rate of LLT in the 4v4SSG against HLT was $169.14 \pm 7.71$ beats $\cdot \min ^{-1}\left(88.17 \pm 2.76 \%\right.$ of $\left.\mathrm{HR}_{\text {peak }}\right)$ and $160.80 \pm 12.09$ beats $\cdot \mathrm{min}^{-1}\left(83.05 \pm 3.84 \%\right.$ of $\left.\mathrm{HR}_{\text {peak }}\right)$ against LLTs.

The statistical analysis showed significant differences between the average heart rate of teams in the $4 \mathrm{v} 4 \mathrm{SSG}$ against different level teams $(F=4.15 ; p=.014$; $\omega^{2}=0.32$ ). Detailed analysis showed significantly lower average heart rate achieved by the HLTs in the 4v4SSG against LLTs than against HLTs (Table 1; $p=.013$ ). Further, lower level teams reached significantly higher average heart rates in the $4 \mathrm{v} 4 \mathrm{SSG}$ against HLTs than in LLTs mutual 4v4SSG (Table 2; $p=.034$ ). In addition, significantly higher average heart rate achieved the LLTs than HLTs in their mutual 4v4SSG $(p=.006)$.

When we examined separated heart rate zones we found out that the performance level of opponents brought about significant differences in time spent in the heart rate zone $<75 \% \operatorname{HR}_{\text {peak }}(F=7.27 ; p=.001$; $\left.\omega^{2}=0.48\right)$ and $85-90 \%$ of $\operatorname{HR}_{\text {peak }}(F=3.19 ; p=.038$;

Table 1

The effect of opponents' level in teams with higher or lower level of performance

\begin{tabular}{|c|c|c|c|c|}
\hline Variable & Team level & Opponent level & Mean $\pm S D$ & $p$ \\
\hline \multirow{4}{*}{$\begin{array}{l}\text { Average heart rate } \\
\left(\text { beats } \cdot \mathrm{min}^{-1}\right)\end{array}$} & \multirow[t]{2}{*}{ Lower } & Lower & $160.8 \pm 12.1$ & \multirow[t]{2}{*}{.034} \\
\hline & & Higher & $169.1 \pm 7.7$ & \\
\hline & \multirow[t]{2}{*}{ Higher } & Lower & $149.9 \pm 10.8$ & \multirow[t]{2}{*}{.013} \\
\hline & & Higher & $161.7 \pm 7.1$ & \\
\hline \multirow[t]{4}{*}{$<75 \%(\%)$} & \multirow[t]{2}{*}{ Lower } & Lower & $27.2 \pm 6.7$ & \multirow[t]{2}{*}{.896} \\
\hline & & Higher & $21.5 \pm 5.6$ & \\
\hline & \multirow[t]{2}{*}{ Higher } & Lower & $42.5 \pm 10.8$ & \multirow[t]{2}{*}{.003} \\
\hline & & Higher & $22.0 \pm 11.6$ & \\
\hline \multirow[t]{4}{*}{$85-90 \%(\%)$} & \multirow[t]{2}{*}{ Lower } & Lower & $24.2 \pm 7.7$ & \multirow[t]{2}{*}{.259} \\
\hline & & Higher & $28.0 \pm 6.0$ & \\
\hline & \multirow[t]{2}{*}{ Higher } & Lower & $20.8 \pm 8.4$ & \multirow[t]{2}{*}{.035} \\
\hline & & Higher & $29.0 \pm 6.4$ & \\
\hline \multirow[t]{4}{*}{ RPE } & \multirow[t]{2}{*}{ Lower } & Lower & $4.3 \pm 1.1$ & \multirow[t]{2}{*}{.298} \\
\hline & & Higher & $4.9 \pm 0.7$ & \\
\hline & \multirow[t]{2}{*}{ Higher } & Lower & $4.2 \pm 1.1$ & \multirow[t]{2}{*}{.189} \\
\hline & & Higher & $4.4 \pm 0.7$ & \\
\hline \multirow[t]{4}{*}{ Distance (m) } & \multirow[t]{2}{*}{ Lower } & Lower & $1121.8 \pm 63.8$ & \multirow[t]{2}{*}{.036} \\
\hline & & Higher & $1242.3 \pm 55.2$ & \\
\hline & \multirow[t]{2}{*}{ Higher } & Lower & $1025.1 \pm 94.3$ & \multirow[t]{2}{*}{.042} \\
\hline & & Higher & $1124.3 \pm 87.0$ & \\
\hline
\end{tabular}

Note. $<75 \%=$ time spent in the heart rate zone $<75 \%$ of $\mathrm{HR}_{\text {peak }}, 85-90 \%=$ time spent in the heart rate zone $85-90$ of $\% \mathrm{HR}$ paak, $\mathrm{RPE}=$ rate of perceived exertion, Distance $=$ distance covered. $p=$ statistical significance of Bonferroni test. 
Table 2

The effect of opponents' level in teams with similar level of performance

\begin{tabular}{lll}
\hline Variable & 4v4SSG & $p$ \\
\hline $\begin{array}{l}\text { Average heart rate } \\
\left(\text { beats } \cdot \mathrm{min}^{-1}\right)\end{array}$ & $\begin{array}{l}\text { lower vs lower level } \\
\text { higher vs higher level }\end{array}$ & .195 \\
$<75 \%(\%)$ & $\begin{array}{l}\text { lower vs lower level } \\
\text { higher vs higher level }\end{array}$ & .318 \\
$85-90 \%(\%)$ & $\begin{array}{l}\text { lower vs lower level } \\
\text { higher vs higher level }\end{array}$ & .936 \\
RPE & $\begin{array}{l}\text { lower vs lower level } \\
\text { higher vs higher level }\end{array}$ & .298 \\
lower vs lower level & .37 \\
histance (m) & higher vs higher level & \\
\hline
\end{tabular}

Note. $\quad<75 \%=$ time spent in the heart rate zone $<75 \%$ of $\mathrm{HR}_{\text {peak }}, 85-90 \%=$ time spent in the heart rate zone $85-90$ of \% $\mathrm{HR}_{\text {peak }}$, $\mathrm{RPE}=$ rate of perceived exertion, Distance $=$ distance covered. $p=$ statistical significance of Bonferroni test.

$\left.\omega^{2}=0.25\right)$, but not in $75-85 \% \quad(F=1.25 ; p=.311$; $\left.\omega^{2}=0.04\right)$ and $>90 \%$ heart rate zone $(F=1.09$; $\left.p=.367 ; \omega^{2}=0.01\right)$. The deeper analysis of heart rate zone $85-90 \%$ of $\mathrm{HR}_{\text {peak }}$ revealed that significantly higher time spent in this zone of HLTs in their mutual 4v4SSG than against lower level teams $(p=.035)$. Similarly to average heart rate results significantly lower time spent in this zone of HLTs than LLTs when played mutual $4 \mathrm{v} 4 \mathrm{SSG}(p=.013)$. HLTs in their mutual $4 \mathrm{v} 4 \mathrm{SSG}$ spent significantly higher time in the $<75 \%$ of $\mathrm{HR}_{\text {peak }}$ heart rate zone than against LLTs (Table $1 ; p=.003$ ). This time was also higher compared to the time spent in this zone in mutual LLTs $4 \mathrm{v} 4 \mathrm{SSG}(p=.006)$. Other differences were not significant.

The values of RPE on the end of SSGs are showed in Table 1. We did not find any significant differences $\left(F=1.25 ; p=.298 ; \omega^{2}=0.04\right)$ among RPE at the end of $4 \mathrm{v} 4 \mathrm{SSG}$.
The average distance covered by the teams during 4v4SSG was around $1100 \mathrm{~m}$ (Table 1). The statistical analysis showed significant differences among the average distance covered by different teams during 4v4SSG $\left(F=9.75 ; p=.001 ; \omega^{2}=0.57\right)$. Detailed analysis of measured differences showed significantly higher distance covered by the LLTs in 4v4SSG against HLTs than in LLTs mutual 4v4SSG (Table $1 ; p=.036$ ). And HLTs reached shorter distance covered against LLTs than in HLTs mutual 4v4SSG (Table $1 ; p=.042$ ). Other differences were not significant.

Table 3 shows the technical analysis of the teams during 4v4SSG. We only used the descriptive statistics, because of the small number of involved teams.

\section{Discussion}

Small-sided games are suitable means to develop soccer specific aerobic conditioning despite any disadvantages, as for example, exact control of work intensity (Krustrup, Dvorak, Junge, \& Bangsbo, 2010; Little, 2009). For facilitating of the usage of small-sided games the search for variables affecting the work intensity is needed. Hill-Haas et al. (2011) showed variables (pitch size, rules modifications, number of players, goalkeeper, coach encouragement), which influence work intensity. Dellal et al. (2011) showed that performance level can influence the work load. According to Koklu et al. (2012) the team formation method (including low and high performance differentiation) could be another variable influencing work intensity. The purpose of this study was to determinate the influence of the different level of opponents to internal responses and external loads of players during 4-a-side soccer game. We supposed that the variable of different level of opponents was able to influence the work load and lead to inadequate training impulse for individual players. These

Table 3

Technical actions of the teams during 4v4SSG

\begin{tabular}{lcccc}
\hline Technical action & LLTvLLT & LLTvHLT & HLTvLLT & HLTvHLT \\
\hline Passes & 122 & 91 & 145 & 126 \\
$\%$ passes & 79 & 67 & 81 & 79 \\
Shots & 14 & 11 & 20 & 15 \\
Steals & 18 & 17 & 20 & 16 \\
Turnovers & 10 & 11 & 9 & 12 \\
\hline
\end{tabular}

Note. Each column contains the total number for two 4v4SSG. LLTvLLT $=$ lower level teams mutual $4 \mathrm{v} 4 \mathrm{SSG}$, LLTvHLT $=$ lower level teams in the 4v4SSG against higher level teams, HLTvLLT $=$ higher level teams in the 4v4SSG against lower level teams, HLTvHLT = higher level teams mutual 4v4SSG. $\%$ passes $=$ accuracy of passes. 
findings could facilitate the training evaluation and the individualization of work load during soccer practices.

The measured average heart rates were lower compared to work of Rampinini et al. (2007) who published percentage of average heart rate $88.7 \pm 2.0 \%$ of $\mathrm{HR}_{\text {peak }}$, or Manolopoulos et al. (2012) who found out even $93.5 \pm 1.7 \%$ of $\mathrm{HR}_{\text {peak }}$. On the contrary Dellal, Varliette, Owen, Chirico, and Pialoux (2012) measured $84.7 \pm$ $2.7 \%$ of $\mathrm{HR}_{\text {peak }}$ in amateur players, which is very similar to our results. We think that our data were lower than the first two studies and similar with the third study because of the amateur level of measured players. Indeed, according to Dellal et al. (2011) technical and tactical awareness can limit the performance of the players during $4 \mathrm{v} 4 \mathrm{SSG}$. When higher level teams played their mutual $4 \mathrm{v} 4 \mathrm{SSG}$ and in the $4 \mathrm{v} 4 \mathrm{SSG}$ of lower level teams against higher level teams the players achieved similar average heart rate around $85 \%$ of $\mathrm{HR}_{\text {peak }}$. These values are considered to be a significant stimulus to the cardiovascular system (Hoff et al., 2002).

The comparison of internal responses and external loads during mutual $4 \mathrm{v} 4 \mathrm{vSSG}$ of HLTs and LLTs showed differences in distance covered only (Table 2). Our results are similar to Dellal et al. (2011) who found differences in distance covered and RPE between amateur and professional players during small-sided games. Both results showed that only heart rate measurement can hide the right responses of players to a training session and make individualized planning of training process impossible. The HLTs are able to produce more work load with similar internal response thanks of better metabolic and physical adaptation. The influence of performance level to work load corresponds with results of soccer match analysis (Stolen et al., 2005) which could point good validity of small-sided games as means of specific aerobic conditioning development.

Other results of this study demonstrated that the work intensity was lower in HLTs when played against LLTs and similarly LLTs had significantly higher average heart rate against HLTs than LLTs. Both average heart rate and distance covered showed the same tendencies. HLTs achieve with lower average heart rate and concurrently shorter distance covered than LLTs. A higher number of turnovers and lower number of passes of LLTs showed that they did not control the ball for a longer time. This fact was probably transferred to longer time spent in the $85-90 \%$ of $\mathrm{HR}_{\text {peak }}$, shorter in the $<75 \%$ of $\mathrm{HR}_{\text {peak}}$, and longer distance covered, which resulted in shorter time for recovery after the high intensity bursts. The work/rest ratio is considered to be an origin of rate of fatigue because of insufficient $\mathrm{PCr}$ resynthesis and disposing of metabolic by products including the accumulation of potassium in muscle interstitium (Gaitanos, Williams, Boobis, \&
Brooks, 1993; Glaister, 2005; Hill-Haas, Rowsell, Dawson, \& Coutts, 2009). Conversely, HLTs made many more passes with higher accuracy and shots than LLTs in their mutual game. Thanks to better positioning game of HLTs, they expended less effort on ball possession than LLTs and to develop good shooting situation. According to Gamble (2007) specific training format of conditioning players should aim to impose proportionate stresses on metabolic and physiological systems corresponding to those typically experienced during game. The differences in the work/rest ratio could lead to different responses to intermittent work of players to the same practice and could create the discrepancies in metabolic adaptations. These applied SSGs could lead to the overloading or undertraining of the players without their coaches' knowledge. It could contradict all positives of small-sided games usage in the practice. The practices could not lead to provision of a progressive training load over time. Our results indicated that the variable of the performance level of opponent team could compromise the progressive individualized development of the teams with larger performance differences.

According to Coutts, Rampinini, Marcora, Castagna, and Impellizzeri (2009) and Hill-Haas et al. (2011) RPE is a valid and objective method of work intensity evaluation. On the contrary internal and external load indicators of RPE did not show significant differences among 4v4SSG. The RPE of lower level teams is slightly higher in the 4v4SSG against higher level teams but negligibly. The perceived work intensity moved from four to five, which corresponds to work intensity around $80 \%$ of $\mathrm{HR}_{\text {peak }}$. The value of RPE could be influenced by the duration of work intervals (Fanchini et al., 2011) or size of the pitch (Casamichana \& Castellano, 2010) but it seems that the performance level of the opponent teams formation do not influence, although the internal and external load indicators are different. The differences in the work intensity caused by the performance level of the opponent teams could be hidden to the coach, when only rate of perceived exertion is used. According to our results the players in our study underestimated the work intensity in comparison with the results heart rate measurement. This underestimation was independent of the level of players participated on the 4v4SSG.

Identified results in the group of students with heterogeneous levels of soccer performance indicated that the opponent's performance level could influence the internal responses and external loads of the players and compromise progressive training load over time. These findings could suggest that we could find similar tendencies in youth where we could expect heterogeneous performance level. 
Due to the group of subjects used with heterogeneous levels of soccer performance, further research in this direction is very important in amateur and professional soccer teams, where the differences may not be so large.

\section{Conclusions}

The results of this study demonstrated that the performance level of opponents influences internal and external load of the players. It could compromise progressive individualized development of the teams with larger performance differences. Every coach should be aware of this variable to reach equal relative intensity of the game. Appropriate use of small-sided games is the way to work in the team with individualized training load, where the endurance training, technical, and tactical training are connected. Therefore, the coach can create individualized and specific soccer practices. The results showed that these differences in work intensity can be hidden, when only rate of perceived exertion is used.

\section{References}

Alexandre, D., da Silva, C. D., Hill-Haas, S., Wong, D. P., Natali, A. J., de Lima, J. R. P., \& Karim, C. (2012). Heart rate monitoring in soccer: Interest and limits during competitive match play and training, practical application. Journal of Strength and Conditioning Research, 26, 2890-2906.

Aslan, A. (2013). Cardiovascular responses, perceived exertion and technical actions during small-sided recreational soccer: Effects of pitch size and number of players. Journal of Human Kinetics, 38, 95-105.

Bangsbo, J., Iaia, F. M., \& Krustrup, P. (2008). The Yo-Yo intermittent recovery test: A useful tool for evaluation of physical performance in intermittent sports. Sports Medicine, 38, 37-51.

Bangsbo, J., Mohr, M., \& Krustrup, P. (2006). Physical and metabolic demands of training and match-play in the elite soccer player. Journal of Sports Sciences, 24, 665-674.

Casamichana, D., \& Castellano, J. (2010). Time-motion, heart rate, perceptual and motor behaviour demands in small-sides soccer games: Effects of pitch size. Journal of Sports Sciences, 28, 1615-1623.

Castagna, C., Impellizzeri, F. M., Chaouachi, A., Ben Abdelkrim, N., \& Manzi, V. (2011). Physiological responses to ball-drills in regional level male basketball players. Journal of Sports Sciences, 29, 1329-1336.

Castellano, J., Casamichana, D., \& Dellal, A. (2013). Influence of game format and number of players on heart rate responses and physical demands in small-sided soccer games. Journal of Strength and Conditioning Research, 27, 1295-1303.
Coutts, A. J., Rampinini, E., Marcora, S. M., Castagna, C., \& Impellizzeri, F. M. (2009). Heart rate and blood lactate correlates of perceived exertion during small-sided soccer games. Journal of Science and Medicine in Sport, 12, 79-84. da Silva, C. D., Impellizzeri, F. M., Natali, A. J., de Lima, J. R. P., Bara, M. G., Silami-Garcia, E., \& Marins, J. C. B. (2011). Exercise intensity and technical demands of smallsided games in young Brazilian soccer players: Effect of number of players, maturation, and reliability. Journal of Strength and Conditioning Research, 25, 2746-2751.

Dellal, A., Hill-Haas, S., Lago-Penas, C., \& Chamari, K. (2011). Small-sided games in soccer: Amateur vs. professional players' physiological responses, physical, and technical activities. Journal of Strength and Conditioning Research, 25, 2371-2381.

Dellal, A., Varliette, C., Owen, A., Chirico, E. N., \& Pialoux, V. (2012). Small-sided games versus interval training in amateur soccer players: Effects on the aerobic capacity and the ability to perform intermittent exercises with changes of direction. Journal of Strength and Conditioning Research, 26, 2712-2720.

Fanchini, M., Azzalin, A., Castagna, C., Schena, F., Mccall, A., \& Impellizzeri, F. M. (2011). Effect of bout duration on exercise intensity and technical performance of smallsided games in soccer. Journal of Strength and Conditioning Research, 25, 453-458.

Gaitanos, G. C., Williams, C., Boobis, L. H., \& Brooks, S. (1993). Human muscle metabolism during intermittent maximal exercise. Journal of Applied Physiology, 75, 712-719.

Glaister, M. (2005). Multiple sprint work: Physiological responses, mechanisms of fatigue and the influence of aerobic fitness. Sports Medicine, 35, 757-777.

Hill-Haas, S., Coutts, A., Rowsell, G., \& Dawson, B. (2008). Variability of acute physiological responses and performance profiles of youth soccer players in small-sided games. Journal of Science and Medicine in Sport, 11, 487-490.

Hill-Haas, S. V., Dawson, B., Impellizzeri, F. M., \& Coutts, A. J. (2011). Physiology of small-sided games training in football: A systematic review. Sports Medicine, 41, 199-220.

Hill-Haas, S. V., Rowsell, G. J., Dawson, B. T., \& Coutts, A. J. (2009). Acute physiological responses and time-motion characteristics of two small-sided training regimes in youth soccer players. Journal of Strength and Conditioning Research, 23, 111-115.

Hoff, J., Wisloff, U., Engen, L. C., Kemi, O. J., \& Helgerud, J. (2002). Soccer specific aerobic endurance training. British Journal of Sports Medicine, 36, 218-221.

Hulka, K., Cuberek, R., \& Svoboda, Z. (2014). Time-motion analysis of basketball players: A reliability assessment of Video Manual Motion Tracker 1.0 software. Journal of Sports Sciences, 32, 53-59.

Impellizzeri, F. M., Marcora, S. M., Castagna, C., Reilly, T., Sassi, A., Iaia, F. M., \& Rampinini, E. (2006). Physiological and performance effects of generic versus specific aerobic training in soccer players. International Journal of Sports Medicine, 27, 483-492.

Koklu, Y., Ersoz, G., Alemdaroglu, U., Asc, A., \& Ozkan, A. (2012). Physiological responses and time-motion characteristics of 4-a-side small-sided game in young soccer 
players: The influence of different team formation methods. Journal of Strength and Conditioning Research, 26, 3118-3123.

Krustrup, P., Dvorak, J., Junge, A., \& Bangsbo, J. (2010). Executive summary: The health and fitness benefits of regular participation in small-sided football games. Scandinavian Journal of Medicine and Science in Sports, 20, 132-135.

Krustrup, P., Mohr, M., Nybo, L., Jensen, J. M., Nielsen, J. J., \& Bangsbo, J. (2006). The Yo-Yo IR2 test: Physiological response, reliability and application to elite soccer. Medicine \& Science in Sports \& Exercise, 38, 1666-1673.

Little, T. (2009). Optimizing the use of soccer drills for physiological development. Strength and Conditioning Journal, 31(3), 67-74.

Little, T., \& Williams, A. G. (2006). Suitability of soccer training drills for endurance training. Journal of Strength and Conditioning Research, 20, 316-319.

Mallo, J., \& Navarro, E. (2007). Physical load imposed on soccer players during small-sided training games. Journal of Sports Medicine and Physical Fitness, 48, 166-171.

Manolopoulos, E., Kalapotharakos, V. I., Ziogas, G., Mitrotasios, M., Spaneas, K. S., \& Tokmakidis, S. P. (2012).
Heart rate responses during small-sided soccer games. Journal of Sports Medicine \& Doping Studies, 2(2), 36-39.

McMillan, K., Helgerud, J., Macdonald, R., \& Hoff, J. (2005). Physiological adaptations to soccer specific endurance training in professional youth soccer players. British Journal of Sports Medicine, 39, 273-277.

Mohr, M., Krustrup, P., \& Bangsbo, J. (2005). Fatigue in soccer: A brief review. Journal of Sports Sciences, 23, 593-599.

Rampinini, E., Impellizzeri, F. M., Castagna, C., Abt, G., Chamari, K., Sassi, A., \& Marcora, S. M. (2007). Factors influencing physiological responses to small-sided soccer games. Journal of Sports Sciences, 25, 659-666.

Reilly, T. (2005). An ergonomics model of the soccer training process. Journal of Sports Sciences, 23, 561-572.

Sjokvist, J., Laurent, M. C., Richardson, M., Curtner-Smith, M., Holmberg, H. C., \& Bishop, P. A. (2011). Recovery from high-intensity training sessions in female soccer players. Journal of Strength and Conditioning Research, 25, 1726-1735.

Stolen, T., Chamari, K., Castagna, C., \& Wisloff, U. (2005). Physiology of soccer: An update. Sports Medicine, 35, 501-536.

Stone, N. M., \& Kilding, A. E. (2009). Aerobic conditioning for team sport athletes. Sports Medicine, 39, 615-642. 